\title{
Inquiry and flow in science education
}

\author{
Jakob Gyllenpalm ${ }^{1}$
}

Received: 10 October 2016/Accepted: 3 November 2016/Published online: 22 May 2017

(C) The Author(s) 2017. This article is an open access publication

\begin{abstract}
Ellwood's and Abrams's paper, Students's social interaction in inquiry-based science education: how experiences of flow can increase motivation and achievement, describes two groups of students and their experiences in an extended inquiry unit. For one of these, the Off-Campus group, several educational aspects were enhanced compared with the group that stayed on campus for their fieldwork. In the analysis this was related to the nature and quality of students' social interactions during the project and their experiences of flow. This forum article seeks to expand and reframe some of the interpretations made by the authors concerning the role of time, place and attention for setting up conditions for experiences of flow in general, and in scientific inquiry in particular. A comparison with the result from research on wait-time is made, and the significance of place and social interactions are related to a typology of attention helpful for understanding Flow theory. It is suggested that an additional finding may be that there are certain moments in an inquiry unit where slowing down the tempo of instruction to allow for feedback and discussion is particularly important, because doing so can significantly alter the subsequent development and quality of students' social interactions, experiences of flow, and consequently learning. Implications for science teaching and teacher education are discussed.
\end{abstract}

Keywords Inquiry $\cdot$ Flow $\cdot$ Attention $\cdot$ Wait-time $\cdot$ Social interactions $\cdot$ Teacher education

Lead Editor: Per-Olof Wickman.

This review essay addresses issues raised in Robin Ellwood' and Eleanor Abrams' paper entitled: Students' social interaction in inquiry-based science education: how experiences of flow can increase motivation and achievement. DOI:10.1007/s11422-016-9769-x.

Jakob Gyllenpalm

jakob.gyllenpalm@mnd.su.se

1 Department of Mathematics and Science Education, Stockholm University, 10691 Stockholm, Sweden 
Everybody wants to have flow! And there seems to be little doubt that the educational experience was enhanced for students in the study by Robin Ellwood and Eleanor Abrams on social interactions and flow in inquiry-based science education. Two groups of students in an eight-grade science class, consisting of four girls in each group, were observed during an inquiry unit spanning over 45 school days devoted to the study of bird behavior in nature. Motivation, enthusiasm, the cognitive level of research questions posed, the complexity of investigations, resolving difficulties, collaboration, the depth of analytical discussions, creativity in interpreting data and developing explanations, the quality of final end products, and a sense of achievement were all mentioned as elevated in the OffCampus group compared with the On-Campus group. In the analysis this was related to a higher prevalence of experiences of flow. The one thing that was only slightly higher for the Off-Campus group was the scores on regular-type school assignments. This, however, may say more about this type of assignments than the students' learning. But what did these students really learn then, and in particular concerning science? And, how can these gains be understood in relation to the particulars of the two cases studied? In this commentary I will try to expand on the analysis given by Ellwood and Abrams and what it could mean for science education.

In their study instances of flow were used to describe and explain the dynamics of students' educational experience. It is an interesting and relevant use of Flow theory, although there are methodological issues regarding the collection and analysis of data to "measure" instances of flow-not an easy task at all. Accepting these for the moment however, I want to focus on the analysis of the conditions for flow as described in their paper. The theoretical framework is based on three conditions for experiencing flow in an activity: clear goals, immediate feedback, and a balance between challenges and skills. For the Off-Campus group these conditions were supported by three aspects that separated it from the On-Campus group: the additional time given, the off-campus location, and the use of debriefing circles in which students and teacher regularly engaged in discussing the progress of their projects. As the research question in this study focused on how social interactions relate to students' motivation and achievement, the significance of these interactions stand out in the interpretation of data, and in particular the debriefing circles. However, I want to begin by giving some more consideration to the aspects of time and location, and their relation to the role of attention - an integral part of Flow theory not emphasized in their paper.

The Off-campus group was given more time than the On-Campus group, and this seems to support the other two aspects unique to the Off-Campus group in contributing to their enhanced experience. More time was required to transfer to the off-campus location, and once in place more time was given and therefore also structured differently than in the normal classroom. In particular, the increased time made it possible for the teacher to organize the debriefing circles, and allowed for other kinds of social interactions to take place and develop as well. Both groups occasionally squandered time we are told, but the more generous margins for the Off-Campus group made this less problematic, and possibly even creatively generative. In fact "time" is mentioned at 98 places in the paper, compared with "social interactions" that appears 51 times. But even though the time factor is noted and commented on by the authors, I believe there is more that needs to be said about it.

The idea of "flow" is dependent on notions of the dynamic, the moving, the changing, and the rhythmical—in a word; time. Yet it is somewhat difficult to get a grip on exactly how time was structured differently for the two groups in this study. The difference lies in Phase 2 of the project where the total time for fieldwork was $300 \mathrm{~min}$ for the On-Campus group and $720 \mathrm{~min}$ for the Off-Campus group. There is no mentioning of time to travel to 
the site so I take this to be the effective time for fieldwork as stated. Out of this a total of 80 min was used in On-Campus group to develop research ideas and explore the area, and a corresponding $150 \mathrm{~min}$ in the Off-Campus group. The discrepancy is then reduced from 70 to $55 \mathrm{~min}$ in a later comment by the authors. This leaves quite some time unaccounted for but my interpretation is that the remaining time of Phase 2 was spent actually doing the investigations, that is to say to collect and analyze data. For the On-Campus group this was then $220 \mathrm{~min}$ and for the Off-Campus group $570 \mathrm{~min}$, give or take $15 \mathrm{~min}$ that are a bit ambiguously accounted for.

\begin{tabular}{lcll}
\hline Time-structure in phase 2 of the project & $\begin{array}{l}\text { On-campus } \\
(\mathrm{min})\end{array}$ & Off-campus (min) & $\begin{array}{l}\text { Differential } \\
\text { factor }\end{array}$ \\
\hline $\begin{array}{l}\text { Total time for fieldwork } \\
\begin{array}{l}\text { Total time to explore potential research } \\
\text { area and develop research ideas }\end{array}\end{array}$ & 300 & 720 & 2.4 \\
\begin{tabular}{l} 
Total time to collect and analyze data \\
\hline
\end{tabular} & 220 & 150 (or 135?) & $1.9(1.7)$ \\
\hline
\end{tabular}

It is not entirely clear if the time difference between the groups was in fact intentional or unintentional, but perhaps that is not so relevant. What is relevant and interesting to note though is that the total time difference in Phase 2 is a factor of 2.4. This reminds me of the now almost forgotten research on wait-time by Mary Budd Rowe (1986). What it demonstrated was that when science teachers (who tended to wait on average $<1 \mathrm{~s}$ after asking a question before letting a student respond to it, and also before commenting the answer) increased this time by a factor of 2.7, a number of qualitative features of the classroom interaction tended to develop. For students the length of responses increased by 300-700\%, arguments became more logical and were given better support, speculative thinking increased, the number of questions asked increased, student-student exchange increased, failures to respond decreased, disciplinary moves decreased, voluntary and spontaneous participation in discussions increased, and students confidence in their answers increased. For teachers their responses tended to show greater flexibility, they asked fewer but cognitively more advanced questions, and their expectations of the performance of their students increased. The last aspect is important in itself and related to the Pygmalion effect, as describe by Barbara Rumain (2010); that the performance of students tends to improve if their teacher holds positive expectations regarding their ability.

Slowing down the rhythm of classroom interactions thus seems to open up and change the rules of the game, allowing valuable qualities to emerge that need more time to develop. Interestingly also, Rowe (1986) reports on different attempts to help teachers learn to slow down their classroom interactions below the magic $2.7 \mathrm{~s}$ threshold. Merely informing teachers was not enough and quite time-consuming procedures were found to be necessary, resulting in the conclusion that a "quick fix for this variable (wait-time) may not be feasible" (p. 47). In other words, there seems to be no fast way to slow down-but the present study shows that a change in context may help. With this background it is not surprising that the Off-Campus group experienced many gains in all sorts of dimensions. And the fact that the increase in the time factor is so similar to that found in the wait-time research is, I think, intriguing. This leaves the question open to the role of the actual inquiry and science parts of the educational experience taken as a whole. But, before returning to this question still a few more comments regarding time are necessary. 
Modern life is ruled by the time-fabric of society, its rhythms, repetitions, intervals and breaks. And there are few areas in society in which the organization of time is so penetrating on all scales as in schools. The schedule is the medium through which the abstract flow of Kronos is compartmentalized, divided and subdivided to control the movements and minds of teachers and students. All teachers and students have had the experience of rushing from one class to the next, sometimes without time even for a bathroom break. It is an organization set up in the image of a factory with parallel assembly lines feeding each other, in need of constant and merciless synchronization-casualties are to be expected. Based on Kevin Rathunde's (2009) and Martin Ashley's (2009) descriptions of Waldorf and Montessori schools, it is possible that the conditions for both experiences of authentic inquiry and flow are more available in schools that work intentionally with avoiding the problems of a scattered daily and weekly schedule. Also, in flow the activity is its own reward and an additional condition for flow sometimes emphasized is therefore that the fear of failure is reduced, as in the study of creativity and flow in music by Raymond MacDonald, Charles Byrne and Lana Carlton (2006). This leads to questions concerning the role of grades in school and how they affect educational experiences. Here more comparative research is needed, and in this context the present study raises questions about the organization of time in schools in general. Whereas Kronos is the mechanical clocktime of celestial bodies and watches, Kairos refers to the quality of time, significant moments or experiences, serendipity, and in particular: timing. It seems to me that the most significant moment that separates the two cases in this study is the part where students explore the sites and develop their research questions. The amount of time and quality of feedback given during this phase seems to reverberate through the rest of the entire project. Knowing that there are specific moments to look for in an inquiry process, when slowing down is especially important, may be the most important advice this study has to offer to teachers.

In contrast to the authors, I also believe that the different context for the Off-Campus location was more than just a "fun" and "novel" place. Is it not possible for example that a part of its function may have been to help the students and their teacher to slow down? People go away for vacations to vacate their minds and life of their busy daily schedules, often in close proximity to nature, and I cannot help but think when reading about this study that something similar might have happened here. But, perhaps even more importantly, the novel location may also be understood as a focusing lens for attention by eliminating many of the usual distractions of normal school life. The role of attention is a significant part of Flow theory mentioned but not emphasized in the paper by Ellwood and Abrams. Mihaly Csikszentmihalyi (1990), who introduced "flow" as a concept in psychology, followed William James in describing attention as a form of psychic energy that can be directed with the will. This, however, is often a far too positive assertion. The honest and meticulous self-observer will have to confront the unflattering insight that we cannot control our attention to the degree that we would like to think more often than we want to admit. Many psychophysical practices (e.g. yoga, Tai Chi, certain forms of dance and music, calligraphy, archery etc.) have been devised to both demonstrate this fact, and to develop and strengthen control over attention. The thousands of hours of practice needed to master such complex arts and gain control over attention is a clue for understanding the role of attention in Flow theory in general, and in this study in particular.

Although I have not systematically reviewed all research there is on attention, there is one idea I have found to be of value to better understand its nature and role in establishing flow. It is described most concisely by David Seamon (1990) and consists of a division of attention into three modes called: non-attention, attracted attention and directed attention. 
Non-attention is scattered or automatic (random) attention with minimal conscious directing of it. Attracted attention is attention drawn in by an external object by its emotional pull in the form of beauty, fear or unexpectedness etc. And, directed attention involves conscious effort to focus attention on an object e.g. the finger positions when learning to type, or a difficult mathematical problem. Something similar to these three modes can be seen in the writings of Csikszentmihalyi (1990) but it is not developed there explicitly. The most significant point here, however, is that non-attention is more prevalent in our daily lives than we would like to admit, and that a certain training and discipline to achieve more sustained levels of directed attention is necessary for increasing experiences of flow. As with any training more help is needed initially and the context for the OffCampus group can be thought of as training wheels in this process of directing attention. The debriefing circles can likewise be understood as a kind of focusing lens for attention by supporting an intermediate state of partly attracted attention. Supported by the physical setting and extra time, the debriefing circles are based on rules for social interaction established by the teacher in co-operation with the students. As described in this study they were a key to set up the other conditions for flow by providing immediate feedback and help students balance challenges with skills in the planning of their investigations.

This brings me to the role of scientific inquiry and the ideas of inquiry based science education (IBSE) in this study. Csikszentmihalyi (1990) devotes an entire chapter to the possibilities of flow in scientific work, but with a focus on the rule bound nature of scientific thinking and the role of memory as a supportive substrate for flow. In the present study opportunities to "act like a scientist" were described largely in terms of social interactions, including the feedback provided by peers and teachers. Thus, to act like a scientist is in this study connected with experiences of flow in a feedback loop of mutual reciprocity. It draws attention to the significance of minds-on rather than hands-on only for meaningful experiences of inquiry in science education. These are important points, but there is also the unique type of feedback provided by nature in authentic scientific inquiry. Therefore, it would be interesting to know more about how the data collected by the students and the cyclical processes of feedback intrinsic to empirical research contributed to their experiences of flow. Because, in complex creative activities such as scientific inquiry, but also in teaching and for example jazz improvisation, goals and rules develop dynamically and tacitly within an evolving context. Derek Hodson (1996) describes it beautifully like this:

... almost every move that a scientist makes during an inquiry changes the situation in some way, so that the next decisions and moves are made in an altered context. Consequently, doing science is an holistic and fluid activity, not a matter of following a set of rules that requires particular behaviours at particular stages. Science is an organic, dynamic, interactive activity, a constant interplay of thought and action. As it proceeds, the whole is continuously evaluated, re-planned and redirected. (p. 17)

It is in other words: re-search. Identical descriptions could be made of teaching and of jazz improvisation (just try replacing a few words). Alfonso Montuori (1996) has for instance described how the social interactions in schools can be modeled by the dynamics of an improvising jazz group, and Wanda May (1993) calls teaching an "art in the medium of the curriculum" which allows for emergent ends-a possibility inherent in authentic scientific inquiry but often suppressed by explicit educational goals stated in advance and assessed with standardized tests. This means that the dynamics of authentic inquiry in the natural sciences has intrinsic elements that are conducive to flow experiences, here 
enhanced by the extrinsic factors unique to the Off-Campus group. An important question is therefore how the reciprocal relationship between doing inquiry and experiences of flow are related to the degree of openness in inquiry as an educational approach. This connects with the work of myself and colleges on different kinds of inquiry in schools and the need for a more a precise taxonomy of these (Gyllenpalm, Wickman, and Holmgren 2010) as the unspecified "degrees of openness" is often both too vague and ambiguous (Gyllenpalm and Wickman 2011).

It seems clear that the Off-Campus group gained a lot more from this experience than learning facts about birds and biology. It may even be safe to say that they acquired a taste of the emotional experience of creative scientific work. The notion of taste has been used by Per Anderhag, Per-Olof Wickman and Karim Hamza (2015) to understand how teachers help students learn to like science and it is likely that the more authentic inquiry experience for the Off-Campus in its totality led to developing their taste for science. Furthermore, Karen Beard and Wayne Hoy (2010) found that a positive academic attitude (as opposed to a general disposition) contributes for teachers to experience flow in their own learning processes, and Namin Shin (2006) reports that students' self-perception of their skills in relation to a particular challenge is important for flow. This raises questions of how the experiences of teachers and students are interrelated in inquiry teaching, and in particular what the students (and teachers) actually learned about scientific inquiry itself, for example as assessed in the work of Judith Lederman et al. (2014). As it stands however, this study can inform how we as teacher educators can give future teachers a taste of "acting like scientist" in processes of inquiry. This is important as many science teachers who are expected to or want to teach science more along the lines of IBSE (in whatever form) often have very limited personal experience of authentic scientific inquiry. Examining the relationship between Kronos and Kairos throughout inquiry processes and how it relates to students' social interactions, science learning and experiences of flow is useful here. What this study illustrates then, is how Flow theory can help to clarify what it means to experience the thrill of scientific inquiry, and the conditions for creating such experiences - lessons we may well use as inspiration both in schools and for creating a better science teacher education.

Open Access This article is distributed under the terms of the Creative Commons Attribution 4.0 International License (http://creativecommons.org/licenses/by/4.0/), which permits unrestricted use, distribution, and reproduction in any medium, provided you give appropriate credit to the original author(s) and the source, provide a link to the Creative Commons license, and indicate if changes were made.

\section{References}

Anderhag, P., Wickman, P.-O., \& Hamza, K. (2015). Signs of taste for science: A methodology for studying the constitution of interest in the science classroom. Cultural Studies of Science Education, 10(2), $339-368$.

Ashley, M. (2009). Education for freedom: The goal of Steiner/Waldorf schools. In P. A. Woods \& G. J. Woods (Eds.), Alternative education for the 21st century: Philosophies, approaches, visions. New York: Palgrave MacMillan.

Beard, K. S., \& Hoy, W. K. (2010). The nature, meaning, and measure of teacher flow in elementary schools: A test of rival hypotheses. Educational Administration Quarterly, 46(3), 426-458.

Csikszentmihalyi, M. (1990). Flow: The psychology of optimal experience (1st ed.). New York: Harper \& Row. 
Ellwood, R., \& Abrams, E. (2016). Student's social interaction in inquiry-based science education: How experiences of flow can increase motivation and achievement. Cultural Studies of Science Education. doi:10.1007/s11422-016-9769-x.

Gyllenpalm, J., \& Wickman, P.-O. (2011). "Experiments" and the inquiry emphasis conflation in science teacher education. Science Education, 95(5), 908-926.

Gyllenpalm, J., Wickman, P.-O., \& Holmgren, S.-O. (2010). Secondary science teachers' selective traditions and examples of inquiry-oriented approaches. Nordic Studies in Science Education, 6(1), 44-60.

Hodson, D. (1996). Laboratory work as scientific method: Three decades of confusion and distortion. Journal of Curriculum Studies, 28(2), 115-135.

Lederman, J. S., Lederman, N. G., Bartos, S. A., Bartels, S. L., Meyer, A. A., \& Schwartz, R. S. (2014). Meaningful assessment of learners' understandings about scientific inquiry-the views about scientific inquiry (VASI) questionnaire. Journal of Research in Science Teaching, 51(1), 65-83.

MacDonald, R., Byrne, C., \& Carlton, L. (2006). Creativity and flow in musical composition: An empirical investigation. Psychology of Music, 34(3), 292-306.

May, W. T. (1993). Teaching as a work of art in the medium of the curriculum. Theory Into Practice, 32(4), 210-218.

Montuori, A. (1996). The art of transformation: Jazz as a metaphor for education. Holistic Education Review, 9(4), 57-62.

Rathunde, K. (2009). Montessori and embodied education. In P. A. Woods \& G. J. Woods (Eds.), Alternative education for the 21st century: Philosophies, approaches, visions. New York: Palgrave MacMillan.

Rowe, M. B. (1986). Wait time: Slowing down may be a way of speeding up. Journal of Teacher Education, $37(1), 43-50$.

Rumain, B. (2010). How can we help our children succeed? Insights from the psychological literature. Education, 131(2), 315-318.

Seamon, D. (1990). Gurdjieff's presentation of emotions: Toward a phenomenology of affective experience. The Humanistic Psychologist, 18(3), 279-300.

Shin, N. (2006). Online learner's "Flow" experience: An empirical study. British Journal of Educational Technology, 37(5), 705-720.

Jakob Gyllenpalm is a lecturer in science education at Stockholm University, with a special focus on physics education. Research interests include inquiry, laboratory work, the nature of science and interdiciplinarity between the arts and science education. He has taught physics and math in the International Baccalaureate program and is a member of the board of the House of Science in Stockholm, an educational science center providing schools with inquiry and laboratory experiences developed specifically for the Swedish national curriculum. 